\title{
Effects of electron beam irradiation on tin dioxide gas sensors
}

\author{
ZHENG JIAO*, XIAOJUAN WAN, BING ZHAO, HUIJIAO GUO, TIEBING LIU and \\ MINGHONG WU
}

Institute of Nanochemistry and Nanobiology, Shanghai University, Shanghai 201800

MS received 1 August 2007; revised 19 September 2007

\begin{abstract}
In this paper, the effects of electron beam irradiation on the gas sensing performance of tin dioxide thin films toward $\mathrm{H}_{2}$ are studied. The tin dioxide thin films were prepared by ultrasonic spray pyrolysis. The results show that the sensitivity increased after electron beam irradiation. The electron beam irradiation effects on tin dioxide thin films were simulated and the mechanism was discussed.
\end{abstract}

Keywords. Electron beam; irradiation; gas sensor; tin dioxide.

\section{Introduction}

The theory, fabrication and application of semiconducting gas sensors, has been well developed in the last thirty years. However, their limited selectivity and sensitivity are still problematic. The usual methods to improve gas sensing properties of $\mathrm{SnO}_{2}$ gas sensors are doping metal, metal ion, metal oxides etc (Heng et al 2003; Mittal et al 2004; Wurzinger and Reinhardt 2004). Microstructure is an important factor that influences gas sensing properties. There are reports to enhance the gas sensing performance of gas sensors by ultraviolet (Camagni et al 1996; Comini et al 2000, 2001) and plasma (Srivastava et al 1998; Chaturvedi et al 2000) irradiation to modify the surface structure, which will greatly increase sensitivity of tin dioxide gas sensors. In this paper, electron beam irradiation was used to improve the gas sensing properties of $\mathrm{SnO}_{2}$. The effect of electron beam irradiation on the $\mathrm{SnO}_{2}$ gas sensors is studied in this paper and the performance of $\mathrm{SnO}_{2}$ gas sensors can be improved notably.

\section{Experimental}

Tin dioxide thin films were prepared by ultrasonic spray pyrolysis, described in detail earlier (Jiao et al 2003). The electron beam irradiation was performed by a GJ-2 electron accelerator, working at $1.75 \mathrm{MeV}, 2 \mathrm{~mA}$. The irradiation doses were controlled by irradiation for different times.

The gas sensitivity, $S$, is denoted by $R_{\mathrm{a}} / R_{\mathrm{g}}$, where $R_{\mathrm{a}}$ and $R_{\mathrm{g}}$ stand for the resistances of the samples in air and $\mathrm{H}_{2}$ gas, respectively. The resistance of the sample was measured in a gas chamber with an inside stirring fan. The

*Author for correspondence (Zjiao@shu.edu.cn) sample was heated and a thermoregulator controlled its temperature.

\section{Results and discussion}

The sensing curves before and after $1000 \mathrm{kGy}$ electron beam irradiation of $\mathrm{SnO}_{2}$ thin film gas sensors to $\mathrm{H}_{2}$ are shown in figure 1. The response of $\mathrm{SnO}_{2}$ thin film to $\mathrm{H}_{2}$ increased after electron irradiation. The sensitivity of $\mathrm{SnO}_{2}$ gas sensor to $100 \mathrm{ppm} \mathrm{H}_{2}$ is 11.5 before irradiation and 37.5 after irradiation, $\sim 3$ times higher, which proves that the electron beam irradiation will increase gas sensing properties.

The relationship between sensitivity of $\mathrm{SnO}_{2}$ sensor to $50 \mathrm{ppm} \mathrm{H}_{2}$ and electron beam irradiation doses are shown in figure 2 . The sensitivity increases with the raise of elec-

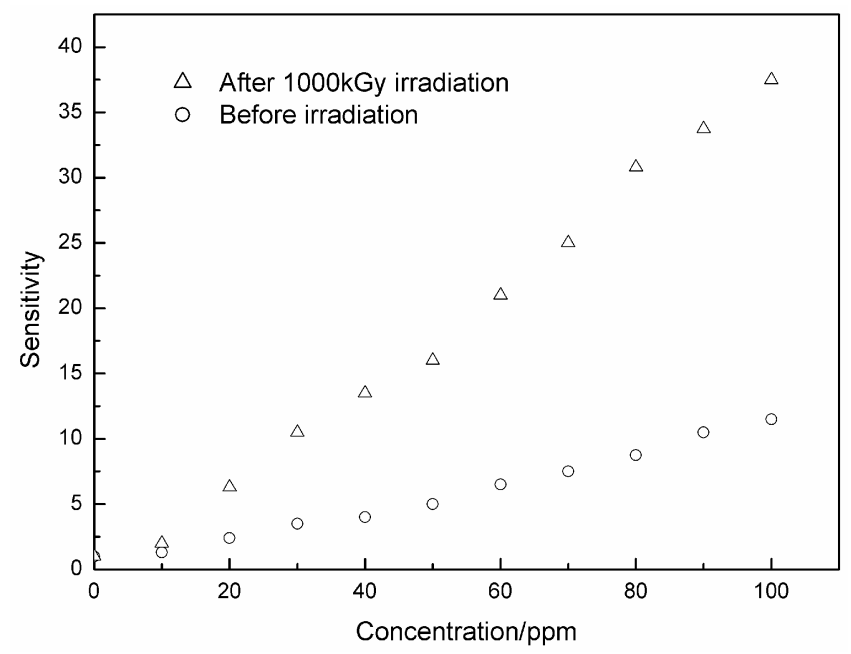

Figure 1. The sensitivity of $\mathrm{SnO}_{2}$ gas sensor to $\mathrm{H}_{2}$ before and after $1000 \mathrm{kGy}$ electron beam irradiation. 


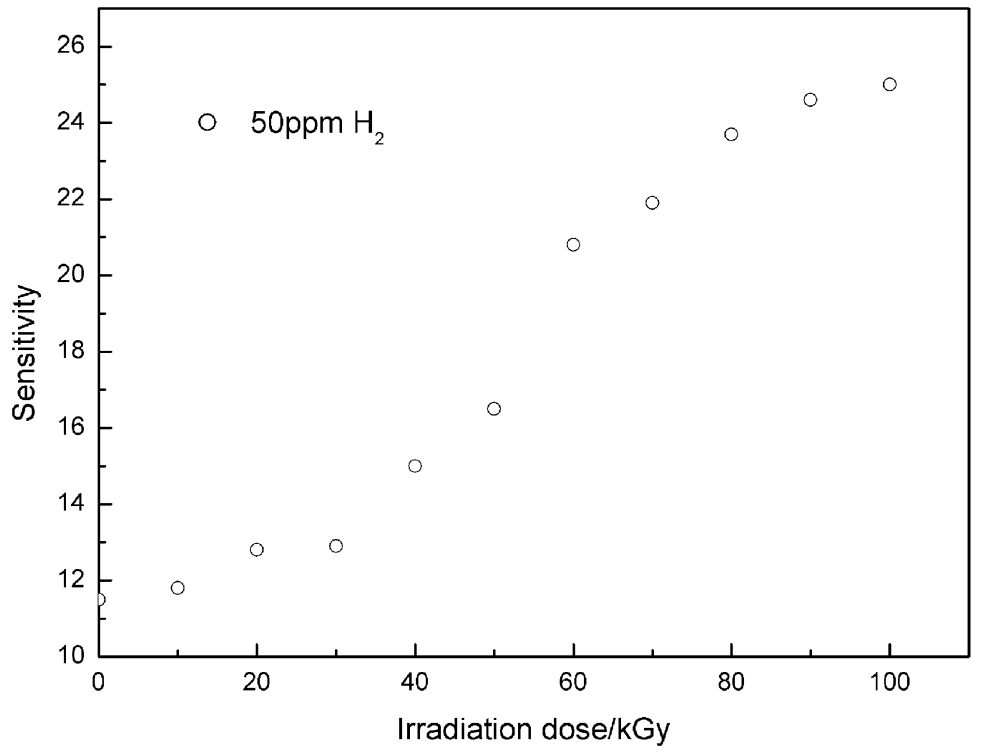

Figure 2. The relationship between sensitivity of $\mathrm{SnO}_{2}$ sensor to $50 \mathrm{ppm} \mathrm{H}_{2}$ and electron beam irradiation doses.
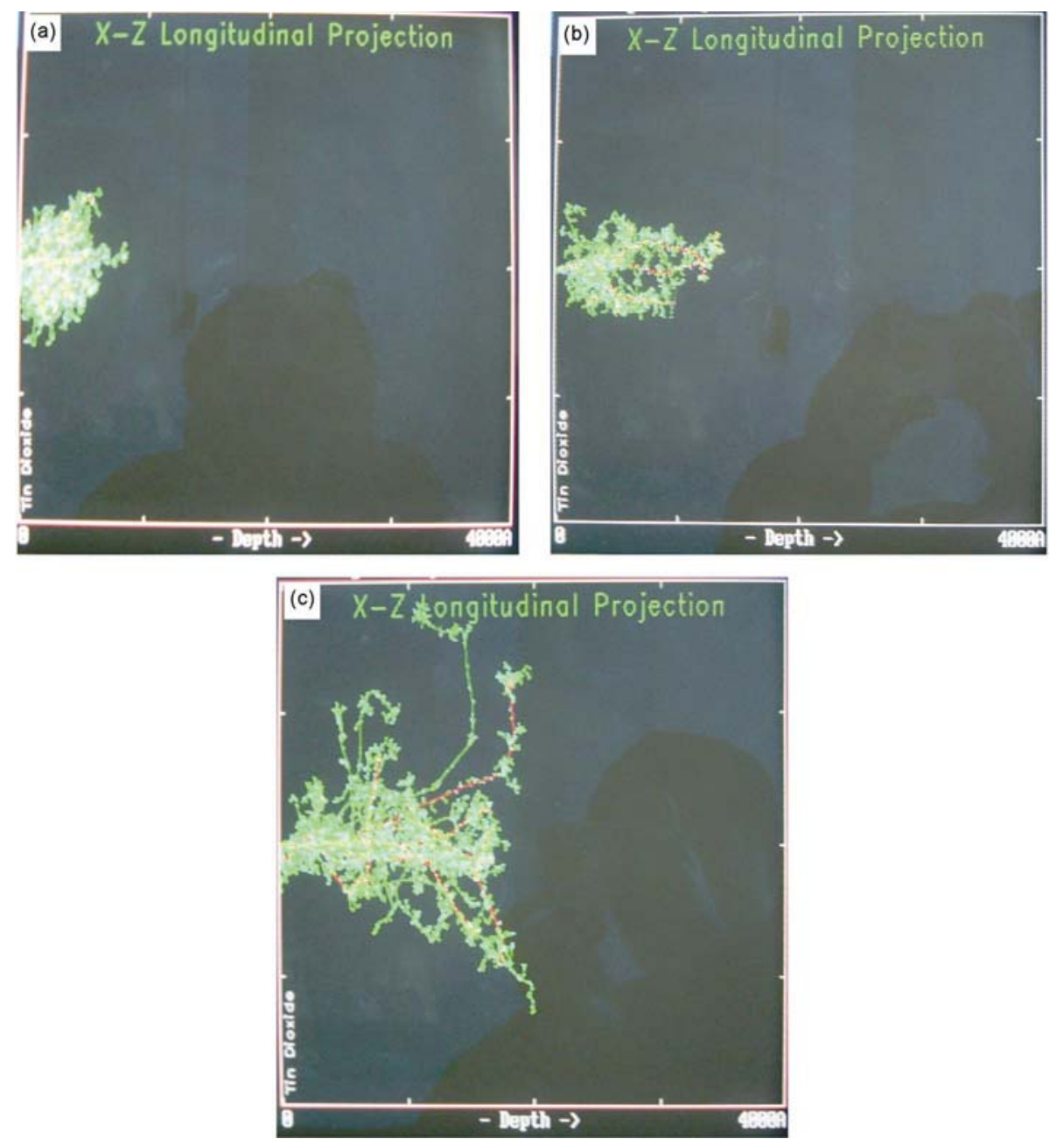

Figure 3. The simulated results of electron beam injecting effects under various irradiation doses: (a) $200 \mathrm{kGy}$, (b) $400 \mathrm{kGy}$ and (c) $800 \mathrm{kGy}$. 
tron irradiation dose. Under low irradiation dose, $<300 \mathrm{kGy}$, the sensitivity of $\mathrm{SnO}_{2}$ thin film shifts slightly, from 300 $850 \mathrm{kGy}$, the sensitivity increases greatly, at $850 \mathrm{kGy}$ and it reaches $24 \cdot 8$. Then the sensitivity reaches maximum and remains stable while continuing to increase irradiation doses.

The electron beam injecting effects into $\mathrm{SnO}_{2}$ surface layer were simulated and are shown in figure 3 . It can be seen that stronger irradiation will inject deep inside the layer and at $200 \mathrm{kGy}$, the affected depth is about $100 \mathrm{~nm}$ (1000 A in image), at $400 \mathrm{kGy}$ the electron beam reached a depth of $150 \mathrm{~nm}$ and at $800 \mathrm{kGy}$, it reached $200 \mathrm{~nm}$. Furthermore, electron beam will not only cause defects in depth, but also in a wider area in the same layer.

According to traditional gas sensing mechanism, polycrystalline metal oxide semiconductor material is composed of grains with different orientations. There are double

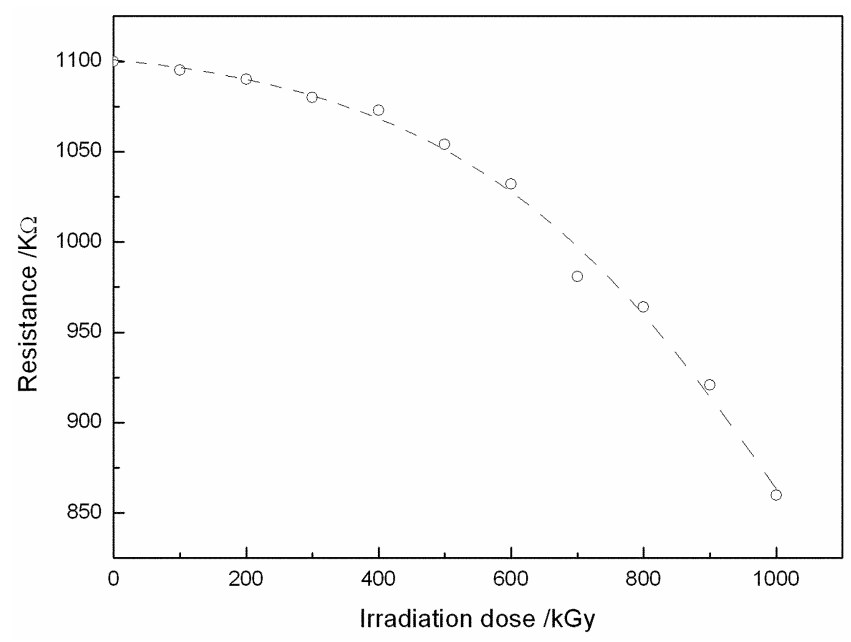

Figure 4. The resistance shift of $\mathrm{SnO}_{2}$ thin film after electron beam irradiation.

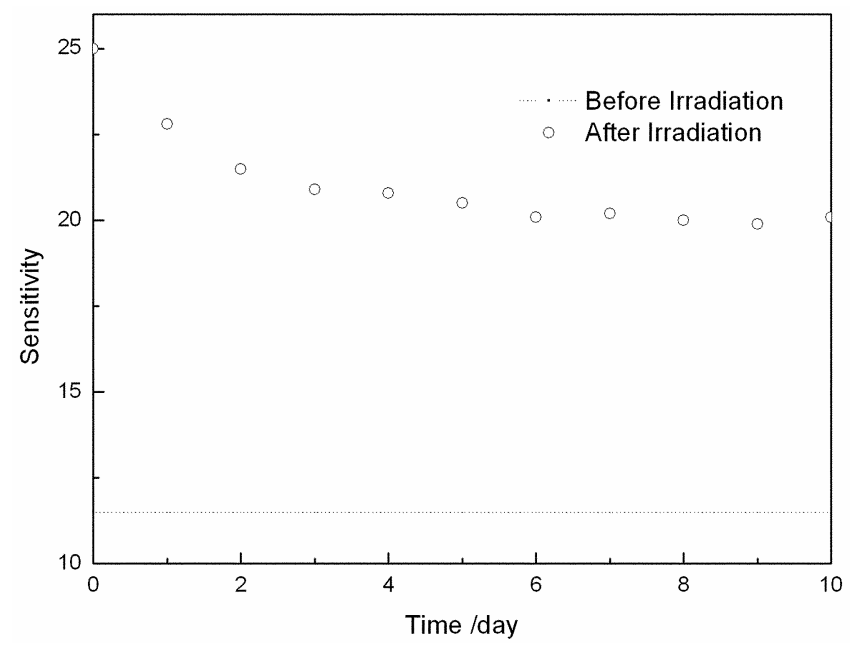

Figure 5. The sensitivity evolution of $\mathrm{SnO}_{2}$ sensor electron beam irradiation. potential barriers between every grain boundaries, which control the conductance of bulk materials. Electron irradiation can affect transport across these grain boundaries by increasing the density of free carriers throughout the material, decreasing the intergrain barrier height by changing the intergrain states charge, and increasing the probability of tunneling through the intergrain barriers by decreasing the depletion layer widths in the adjacent grains.

The resistance shift of $\mathrm{SnO}_{2}$ thin film after electron beam irradiation is shown in figure 4 . The resistance of $\mathrm{SnO}_{2}$ thin film decreases slowly at low irradiation dose, but decreases rapidly under high irradiation dose. The electron beam irradiation will not change the chemical composition of the semiconductor, but produces structural defects. The electron beam irradiation changes the occupancy of the defects by electrons and holes, changes the concentration of the adsorption centres of each given type and the capacity of adsorption on the surface of the semiconductor, these factors caused the decrease of resistance of $\mathrm{SnO}_{2}$ thin film.

Figure 5 shows the sensitivity evolution in several days after electron beam irradiation. The highest sensitivity was obtained just after irradiation and decreases with time. But it will reach a stable value after 4 or 5 days, and still much higher than the sensitivity before irradiation, shown as dashed line in the figure.

\section{Conclusions}

The ultrasonic spray pyrolysis prepared tin dioxide thin film gas sensors were treated by electron beam irradiation. The results show that the bulk resistance decreased and the sensitivity to $\mathrm{H}_{2}$ increased after irradiation. The sensitivity increases more rapidly under high doses of irradiation than under low doses of irradiation. The electron beam irradiation effects were simulated and the mechanism was discussed.

\section{Acknowledgements}

The authors gratefully acknowledge financial support from the MOST 973 program, grant no. 2006CB705604, Qimingxing 05QMX1423, and Shanghai Leading Academic Disciplines (T0105).

\section{References}

Camagni P, Faglia G, Galinetto P, Perego C, Samoggia G and Sberveglieri G 1996 Sensor Actuat. B31 99

Chaturvedi A, Mishra V N, Dwivedi R and Srivastava S K 2000 Microelectr. J. 31283

Comini E, Cristalli A, Faglia G and Sberveglieri G 2000 Sensor Actuat. B65 260 
Comini E, Faglia G and Sberveglieri G 2001 Sensor Actuat B78 73

Heng Lee Yook, Fang Ten Huey, Chern Loh Han and Ahmad Musa 2003 Sensors 383

Jiao Z, Wu M, Qin Z, Lu M and Gu J 2003 Sensors 3285
Mittal S K, Sharma H K and Kumar A S K 2004 Sensors 4 125

Srivastava Roopali, Dwivedi R and Srivastava S K 1998 Sensor Actuat. B50 175

Wurzinger O and Reinhardt G 2004 Sensor Actuat. B103 104 